\title{
The Effect of Human Relation Skill Training Program for Married Couples on the Level of Marital Adjustment of Married Couples.
}

\author{
Mehmet E. SARDOĞAN* \\ T.Fikret KARAHAN*
}

\begin{abstract}
In this study the effect of human relation skill training program with 10 sessions which was developed by researchers on the level of marital adjustment level of married couples were investigated. The working group was consisted of 24 voluntary married couples. Pre - test and post - test model was used with control group and experimental group were consisted 12 individual. Married couples marital adjustment level was measured with "Marital Adjustment Scale" which was developed by Kışlak - Tutarel (1999). The data were analyzed with Mann Whitney U test and Wilcoxon Signed Rank Test. Data handled in this research had shown that married couples who were particapated 10 sessions of human relations skill training program had higher level of marital adjustment than other individuals who were not participated in training program $(\mathrm{P}<.01)$. The findings of this had shown that positive effect on the human relations skill training program had levels of marital adjustment of married couples.
\end{abstract}

Key Words: Marital Adjustment, Married Couple, Human Relations Skill Training Program.

\footnotetext{
* Asist. Prof. Dr., Ondokuz Mayıs University, Department of Psychological Counseling and Guidance.sardogan@omu.edu.tr

* Asist. Prof. Dr., Ondokuz Mayıs University, Department of Psychological Counseling and Guidance. tfikretkarahan@hotmail.com
} 


\section{SUMMARY}

In this study the effect of human relation skill training program with 10 sessions which was developed by researchers on the level of marital adjustment level of married couples were investigated. The working group was consisted of 24 voluntary married couples. Pre - test and post - test model was used with control group and experimental group were consisted 12 individual. Married couples marital adjustment level was measured with "Marital Adjustment Scale" which was developed by Kışlak - Tutarel (1999). To help married couples in terms of problems in marital relations with agreement and cooperation and carrying out an adaptive marriage, experimental group have received an human relations skills training program with 10 sessions.

With this program the aim was developing human relation skills of married couples and using of this skills in solving marital problems. So, couples in this program have chance to perform skills and they can use these skills in their marriage after years and human relations and communication skills can be use in high level of skills. In the first session, problems in marriage and human relations and communication skills of couples were discussed. In this session, it was observed that, male couples'; do not share emotions and beliefs, do not show sympathy in their diffucilties, in disagreement situations behaving in disrespectfull and offensive, in criticism behaving in anger situations, these are observed by females couples. In advance situations male couples'; listening without anger in criticism, diffucilties according to females couples in terms of "I" language with sharing emotions and using confrontative sympathy and using more ordering sentences were observed. Female couples; sharing their emotions, beliefs and desires with more abstract or general expressions were observed by male couples. Couples with dysfunctional communication skills have no sufficient in solving in marital problems.

This situtation, attributed to the couples past lifes and did not have gain effective human relation skills. In 10 sessions in relations of couples the aim was to gain different skills these are; effective listening skill, in listening to use body language to continue communication, expression of emotions with concrete "I" language, to use empathy and to make empathic confrontation, aware of their anger, control of anger, and Express without hurt their couple, and in criticism to continue communication and dealings with beliefs. After each session, there were homeworks to develop skills whic was learned between couples. These practices have been effective on the married couples in terms of marital adjusment levels. The data were analyzed with Mann Whitney U test and Wilcoxon Signed Rank Test. Data handled in this research had shown that married couples who were particapated 10 sessions of human relations skill training program had higher level of marital adjustment than other individuals who were not participated in training program $(\mathrm{P}<.01)$. The findings of this had shown that positive effect on the human relations skill training program had levels of marital adjustment of married couples. 


\title{
Evli Bireylere Yönelik Bir İnsan İlişsileri Beceri Eğitimi Programı'nın Evli Bireylerin Evlilik Uyum Düzeylerine Etkisi
}

\author{
Mehmet E. SARDOĞAN * \\ T. Fikret KARAHAN"
}

ÖZ: $\mathrm{Bu}$ araştırmada araştırmacılar tarafindan geliştirilen 10 oturumluk İnsan İlişkileri Beceri Eğitimi Programı'nın evli bireylerin evlilik uyum düzeyleri üzerindeki etkisi incelenmiştir. Çalışma grubu programa gönüllü olarak katılmak isteyen 24 evli bireyden oluşturulmuştur. Araştırma deseni olarak Kontrol Gruplu Ön-test Sontest Model kullanılmış ve 12 birey deney 12 birey de kontrol grubuna alınmıştır. Araştırmaya katılan evli bireylerin evlilik uyum düzeyleri Kışlak-Tutarel (1999) tarafından Türkiye uyarlaması yapılan "Evlilikte Uyum Ölçeği” ile ölçülmüştür. Verilerin analizinde Mann Whitney U Testi ve Wilcoxon İşaretli Suralar Testi kullanılmıştır. Araştırma bulguları; 10 oturumluk İnsan İlişsileri Beceri Eğitimi Programı'na katılan evli bireylerin evlilik uyum düzeylerinin, programa katılmayan bireylerin evlilik uyum düzeylerinden daha yüksek olduğunu ortaya koymuştur $(\mathrm{p}<.01)$. Elde edilen bulgular, İnsan İlişkileri Beceri Eğitimi Programı'nın evli bireylerin evlilik uyum düzeylerini olumlu yönde etkilediği şeklindedir.

Anahtar Sözcükler: Evlilikte Uyum, Evli Birey, İnsan İlişkileri Beceri Eğitim Programı.

\footnotetext{
* Yrd.Doç.Dr., Ondokuz Mayıs Üniversitesi, Psikolojik Danışma ve Rehberlik Anabilim Dalı sardogan@omu.edu.tr

*Yrd.Doç.Dr., Ondokuz Mayıs Üniversitesi, Psikolojik Danışma ve Rehberlik Anabilim Dalı tfikretkarahan@hotmail.com
} 


\section{Gİiș}

Evlilik, bir erkek ve bir kadın arasında toplum tarafından onaylanmış ilişki (Kottak, 2001); karşılıklı dayanışma, toplumsal onaylama sonucunda gerçekleşen bir sözleşme ve toplumsal yasaklamaların tamamen dışında tutulan cinsel ihtiyaçların doyuma ulaştıııldı̆̆ 1 bir kaynaşma durumu (Özuğurlu, 1985) olarak tanımlanmaktadır. Güvenç de (1984) evliliği tanımlarken, toplumsal normlara göre onaylanmış bir bağın kurulması ve doğumla sonuçlanabilen cinsel ilişkinin toplumsal normlara uygun duruma getirilmesi olarak tanımlamaktadır.

Uyumlu bir evliliğe bağlı olarak gelişen evlilik mutluluğu ve evlilik doyumu, insan yaşamında önemli bir rol oynamakta ve evli bireylerin psikolojik sağlığını yakından etkilemektedir. Evlilik uyumu bozulmaya başladığında bu tablo, eşler ve var ise çocuklar açısından bir yaşam krizine ya da travmaya dönüşmektedir. Bu durum mutlu ya da mutsuz evlilik olgusunu da ortaya çıkarmaktadır. Uyumlu bir evlilik ilişkisi eşlerin evlilikten sağladığı doyumu ve evlilik mutluluğunu etkilerken, diğer değişkenlerle birlikte gittikçe zorlaşan sosyo-ekonomik koşullar karşısında eşlerin psikolojik sağlığını da korumaktadır.

Evlilikte eşlerin mutluluk algılarının üst düzeyde olması ve hem evlilikten hem de birbirlerinden hoşnut olarak doyum sağlaması (Sinha, Mukerjee, 1989) evlilikte uyumu da beraberinde getirmektedir. Spanier (1976) evlilikte uyumu, eşlerin günlük yaşantıya ve yaşantı içinde değişen koşullara uyum sağlaması ve belirli bir süre içinde birbirlerine uygun olarak değişmesi şeklinde tanımlamaktadır. Sabatelli (1988)ise uyumlu evliliği eşlerin birbirleriyle iletişim kurabildiği,evliliğin önemli alanlarında fazla anlaşmazlık yaşanmadığı,anlaşmazlıkların her iki tarafı da hoşnut edecek şekilde çözümlendiği evlilik olarak tanımlamaktadır. Nelson-Jones (1986, s.75), insan ilişkilerinin başlama, geliştirme, sürdürme ve sonlandırma şeklinde dört aşama da gerçekleştiğini; uyumlu evlilik ilişkilerinde sonlandırma aşamasının yalnızca eșlerden birinin ölümüyle mümkün olabileceğini belirtmektedir. Sürdürme aşaması evlilikte yüksek uyumu gerektirmektedir.

Evlilikte eşler arasında kurulan iletişim ile diğer toplumsal ortamlarda başka insanlarla kurulan iletişim arasında önemli bir benzerlik bulunmaktadır. Diğer birç̧ok değişkenle birlikte eşlerin sahip olduğu insan ilişkileri becerileri, evlilikte uyumu güçlendirmekte ya da yaşanan problemleri neredeyse içinden çıkılmaz duruma getirmektedir. Yapılan bilimsel araştırmalar evlilikte uyum ile eşlerde gözlenen irrasyonel düşünceler (Müller, Zyl, 1991); çocuk yetiştirmede ortaya çıkan fikir 
uyuşmazlıkları (Jouriles ve Ark. 1991); eşlerden birinde var olan herhangi bir kronik hastalık (Carter, Carter, 1994); eşlerin benzer kişilik özelliklerine sahip olması (Nemechek, Olson, 1999); eşlerin hastalıkları algılama tarzı ve hastalıklar karşısında gösterdikleri tepkiler (Ming, 2002); eşlerden birinde gözlenen yüksek kayg1 (Dehle, Weiss, 2002); erkeğin geleneksel cinsiyet rollerinin dışına çıkması ev işlerine yardım etmesi (Mc Govern, Meyers, 2002); eşlerden birinde kısırlık ortaya çıkması (Peterson, Newton, Rosen, 2003) ve ailede engelli bir çocuğun bulunması (Risdal, Singer, 2004) gibi değişkenler arasında da önemli ilişkilerin bulunduğunu ortaya koymaktadir.

\section{Problem}

Evlilik yaşamının uyum içinde sürebilmesi, evli bireylerin sahip oldukları insan ilişkileri ve iletişim becerilerinin yeterli düzeyde oluşu ile ilişkili olduğu söylenebilir. $\mathrm{Bu}$ araştırmada araştırmacılar tarafından literatürden yararlanılarak geliştirilen İnsan İlişkileri Beceri Eğitimi Programı'nın; evli bireylerin evlilikte uyum düzeyleri üzerindeki etkililiğinin araştırılması amaçlanmıştır. Yukarıda açıklanan amaca dayalı olarak aşağıdaki denenceler test edilmiştir.

1. İnsan İlişkileri Beceri Eğitimi Programı'na katılan evli bireylerin Evlilikte Uyum Ölçeği son-test puanları, bu programa katılmayan evli bireylerin son-test puanlarına göre daha yüksektir.

2. İnsan İlişkileri Beceri Eğitimi Programı'na katılan deney grubundaki evli bireylerin Evlilikte Uyum Ölçeği son-test puanları, ön-test puanlarına göre daha yüksektir.

\section{YÖNTEM}

Araştırma; İnsan İlişkileri Beceri Eğitimi Programı'nın evli bireylerin evlilik uyum düzeyleri üzerindeki etkisini incelemeye yönelik ön-test sontest kontrol gruplu deneysel bir çalışmadır.

\section{Araştırmaya Katılan Bireyler}

Araştırmada; 2005 yılında Samsun il merkezinde yaşayan evli bireylere Ondokuz Mayıs Üniversitesi Sürekli Eğitim Merkezi'nde duyuru yapılarak, grup yaşantısına dayalı 10 oturumluk "İnsan İlişkileri Beceri Eğitimi Programı” uygulanacağı bildirilmiştir. Bu programa eşiyle birlikte gönüllü olarak, belirlenen gün ve saatlerde katılabileceğini ve evliliğindeki problemlerini aşmak istediğini belirten 38 evli çifte "Evlilikte Uyum Ölçeği (EUÖ)" uygulanmıştır. Uygulama sonucunda Evlilikte Uyum Ölçeği puanları, diğerlerine göre en düşük olan evli çiftlerden 24 kişilik bir çalışma 
grubu, araştırmanın örneklemini oluşturmuştur. Araştırmanın gruplarını oluşturmak için seçkisiz örnekleme yöntemiyle 12 kişiden oluşan deney ve 12 kişiden (6 evli çift) oluşan kontrol grubu olmak üzere iki grup kurulmuştur. Gruplardaki evli çiftlerin yüksek öğrenim mezunu oldukları ve yaşlarının 30-45, evlilik sürelerinin ise 3-16 y1l arasında değiştiği gözlenmektedir. Evlilik uyum düzeyleri açısından deney ve kontrol gruplarının denk olup olmadığını test edebilme amacıyla, veriler üzerinde Mann Whitney U Testi uygulanmış ve iki grubun ön-test puan ortalamaları arasında önemli bir farklılığın bulunmadığı saptanmıştır. Elde edilen sonuç Tablo-1'de verilmiştir.

Tablo-1. Deney ve Kontrol Grubuna Alınan Evli Bireylerin EUÖ Ön-test Puanlarına İlişkin Mann Whitney U Testi Sonuçları

\begin{tabular}{|c|c|c|c|c|c|}
\hline Gruplar & $\mathbf{n}$ & $\begin{array}{c}\text { Sira } \\
\text { Ortalaması }\end{array}$ & $\begin{array}{c}\text { Sira } \\
\text { Toplamı }\end{array}$ & $\mathbf{u}$ & $\mathbf{p}$ \\
\hline Deney & 12 & 13.50 & 162.00 & 60.00 & .487 \\
\cline { 1 - 3 } Kontrol & 12 & 11.50 & 138.00 & & $\mathrm{p}>.05$ \\
\hline
\end{tabular}

Elde edilen bu sonuca dayalı olarak, EUÖ ön-test puan ortalamalarına göre araştırmanın başında deney ve kontrol gruplarının denk sayılabileceği söylenebilir.

\section{Araştırma Deseni}

$\mathrm{Bu}$ araştırmada Kontrol Gruplu Ön-test Son-test Model kullanılmıştır. Araştırmanın bağımsız değişkeni olan insan ilişkileri beceri eğitimi verilmeden önce, deney ve kontrol gruplarına Evlilikte Uyum Ölçeği ön-test uygulaması yapılmıştır. Deney grubuna 10 oturumluk ve haftada iki saatlik oturumlar şeklinde insan ilişkileri beceri eğitimi verilmiş, kontrol grubuna ise hiçbir işlem yapılmamıştır. On oturumluk insan ilişkileri beceri eğitimi sonunda, programın etkililiğini ölçme amacıyla deney ve kontrol gruplarına Evlilikte Uyum Ölçeği son-test uygulaması yapılmıştır.

\section{Veri Toplama Aracı}

Araştırmada problemin incelenebilmesi için gerekli olan veriler Evlilikte Uyum Ölçeği (EUÖ) ile toplanmıştır.

\section{Evlilikte Uyum Ölçeği (EUÖ)}

Toplam 15 maddeden oluşan ölçek, Locke ve Wallace tarafindan geliştirilmiş ve Kışlak-Tutarel (1999) tarafından Türkiye'de geçerlik güvenirlik çalışması yapılmıştır. Ölçekten alınabilecek puanlar 1 ile 60 puan arasında değişmekte olup, yüksek puan evlilikte uyumu, düşük puan da uyumsuzluğu göstermektedir. Ölçek; genel evlilik uyumu ile birlikte aile 
bütçesi, duyguların ifadesi, arkadaşlar, cinsellik ve yaşam felsefesi gibi konularda anlaşma ya da anlaşamama durumunu ve güven, çatışma çözme, boş zaman ve ev dışı etkinliklerde ilişki tarzını ölçmektedir. Ölçeğin güvenirlik çalışmasında; iç tutarlılık katsayısı .84, test yarılama test güvenirliği ise .84 olarak hesaplanmıştır. Test-tekrar test yöntemi ile yapılan güvenirlik çalışmasında pearson momentler çarpımı korelasyon katsayısı .57 olarak hesaplanmıştır. Ölçüt bağıntılı geçerliğinin hesaplanması amacıyla kullanılan Kişilerarası İlişkiler Ölçeği ile EUÖ'nin toplam puanları arasındaki korelasyon katsayısı .12; İlişkilerde Yükleme Ölçeği toplam puanları arasındaki korelasyon katsayısı ise -.54 olarak hesaplanmıştır (Kışlak-Tutarel, 1999, 54-55).

\section{İşlem Yolu}

Araştırmanın bağımsız değişkeni, ön-test ve son-test uygulamaları arasında gerçekleştirilen grup yaşantısına dayalı 10 oturumluk İnsan İlişkileri Beceri Eğitimi Programı'dır. Program araştırmacılar tarafından eklektik bir yaklaşımla bir çok kaynaktan yararlanılarak geliştirilmiştir (Reece, Brandt, 1990; Egan, 1977; Nelson- Jones, 1986; Scott, 1988; Schanake, 1990; Stahlhut, Havkes, 1994; Nutter, Boland, 1982; Stitt, Stitt, 1990; Dowd, Chick, 1982; Atlanta Univ. Human Relations Training Handbook, 1983; Egan, 1994).

$\mathrm{Bu}$ araştırmada deney grubuna uygulanan grup yaşantısına dayalı İnsan İlişkileri Beceri Eğitimi Programı, her hafta sonu yaklaşı iki saatlik oturumlar şeklinde 10 oturumda gerçekleştirilmiştir. İlk oturumda üyeler arasında tanışma, oturumlara devam ve grubun işleyişi hakkında bilgilendirme yapılmıştır. Daha sonra evlilikte ortaya çıkan problemlerle insan ilişkileri becerileri arasındaki ilişki ile ilgili tartışma açılmış ve üyelerin yaşantıları paylaşılmıştır. Sonraki oturumlarda ise eşiyle kurduğu iletişimde kabul, anlayış ve saygı ifade eden tepkiler verebilme, etkin dinleme becerisini kullanabilme, duygu ve düşüncelerini eşine ben dili kullanarak ifade edebilme, duygu ve düşüncelerini eşiyle somut olarak paylaşabilme ve soyut ifadelerden kaçınma, eşinin beden dilini anlayabilme,eşiyle empati kurabilme,eşine yönelik empatik yüzleştirme yapabilme,eşine kendini açma,eşine içtenlik ifade eden tepkiler verebilme, eşiyle ilişkilerinde öfkesini kontrol edebilme ve öfkesini eşiyle ben dili kullanarak paylaşabilme,eşinden gelen eleştiriler karşısında öfkelenmeden ve iletişim engellerini kullanmadan görüş alış-verişinde bulunabilme,eşinin eleştirileri karşısında öz-eleştiri yapabilme ve eşiyle empati kurarak eleştiri yapabilme gibi etkinliklere yer verilmiştir. Her oturumda ele alınan beceri ile ilgili olarak çiftlere eş zamanlı olarak uygulama yaptırılmış ve duyguları paylaşılmıştır. Her oturumun sonunda oturumda üzerinde durulan becerinin 
günlük hayata aktarılması doğrultusunda ödevlendirme yapılmış ve bir sonraki oturumda yaşantıları çiftlerle tartışılmıştır.

\section{Verilerin Analizi}

$\mathrm{Bu}$ araştırmanın yürütülmesi amaciyla oluşturulan deney ve kontrol gruplarındaki evli çiftlerin EÜÖ'nden aldıkları ön-test ve son-test puanları, araştırmanın denencelerini test edecek şekilde düzenlenmiştir. Verilerin analizinde Mann Whitney U Testi ve Wilcoxon İşaretli Sıralar Testi kullanılmış olup, SPSS 11.0 paket programından yararlanılmıştır. Sonuçların yorumlanmasında ise .05 hata payı üst değer olarak alınmıştır.

\section{BULGULAR}

$\mathrm{Bu}$ bölümde araştırmanın denencelerini test edebilme amacıyla yapılan istatistiksel işlemler sonucunda elde edilen bulgulara yer verilmiştir.

Denence-1. “İnsan İlişkileri Beceri Eğitimi Programı'na katılan evli bireylerin EUÖ son-test puanları, bu programa katılmayan evli bireylerin son-test puanlarına göre daha yüksektir."

$\mathrm{Bu}$ denenceyi test edebilme amaciyla, deney ve kontrol grubundaki deneklerin EUÖ son-test puanları üzerinde Mann Whitney U Testi uygulanmış ve sonuç Tablo-2'de verilmiştir.

Tablo-2. Deney ve Kontrol Grubu Deneklerinin EUÖ Son-test Puanlarına Illişkin Mann Whitney U Testi Sonuçları

\begin{tabular}{|c|c|c|c|c|c|}
\hline Grup & n & Sura Ortalaması & Sura Toplamı & u & P \\
\hline Deney & 12 & 16.83 & 202.00 & 20.00 & .003 \\
\cline { 1 - 4 } Kontrol & 12 & 8.17 & 98.00 & & $\mathrm{P}<.01$ \\
\hline
\end{tabular}

Tablo-2'de yer alan istatistiksel veriler; deney ve kontrol grubundaki deneklerin EUÖ son-test puan ortalamaları arasındaki farkın .01 düzeyinde önemli olduğunu göstermektedir. Bu sonuç araştırmanın birinci denencesini doğrulayıcı niteliktedir.

Denence-2. “İnsan İlişkileri Beceri Eğitimi Programı'na katılan deney grubundaki evli bireylerin EUÖ son-test puanları, ön-test puanlarına göre daha yüksektir."

$\mathrm{Bu}$ denenceyi test edebilme amaciyla deney grubundaki deneklerin EUÖ ön-test ve son-test puan üzerinde Wilcoxon İşaretli Sıralar Testi uygulanmış ve sonuç Tablo-3'te verilmiştir. 
Tablo-3. Deney Grubu Deneklerinin EUÖ Ön-test ve Son-test Puanlarına İlişkin Wilcoxon İşaretli Sıralar Testi Sonuçları

\begin{tabular}{|c|c|c|c|c|c|}
\hline $\begin{array}{l}\text { Son - test } \\
\text { Ön - test }\end{array}$ & $\mathbf{n}$ & Sira Ortalaması & Sıra Toplamı & $\mathbf{Z}$ & $\mathbf{P}$ \\
\hline $\begin{array}{l}\text { Negatif } \\
\text { Sira }\end{array}$ & 1 & 1.00 & 1.00 & 2.84 & \multirow{2}{*}{$\begin{array}{c}.004 \\
\mathrm{P}<.01\end{array}$} \\
\hline $\begin{array}{l}\text { Pozitif } \\
\text { Sira }\end{array}$ & 10 & 6.50 & 65.00 & & \\
\hline Eşit & 1 & & & & \\
\hline
\end{tabular}

Tablo-3'te yer alan istatistiksel veriler, deney grubundaki evli bireylerin ön-test ve son-test puanları arasındaki farklılığın .01 düzeyinde önemli olduğunu göstermektedir. $\mathrm{Bu}$ sonuç araştırmanın ikinci denencesini doğrulayıcı niteliktedir.

\section{TARTIŞMA VE YORUM}

$\mathrm{Bu}$ araştırmada, araştırmacılar tarafından geliştirilen İnsan İliş̧kileri Beceri Eğitimi Programı'nın evli çiftlerin evlilik uyum düzeyleri üzerindeki etkisi incelenmiştir. $\mathrm{Bu}$ amaçla 12'şer kişilik deney ve kontrol grupları oluşturulmuştur. Evlilik ilişkilerinde yaşadıkları problemleri uzlaşma ve işbirliği içinde çözebilmelerine ve uyumlu bir evlilik sürdürmelerine yardımcı olma amaciyla, 10 oturum süresince deney grubunda bulunan evli çiftlere insan ilişkileri beceri eğitimi verilmiştir. Bu program ile evli çiftlerin insan ilişkileri becerilerinin geliştirilerek bunları evlilik sorunlarının çözümünde kullanmalarına yardımcı olunması hedeflenmiştir. Böylece programa katılan evli çiftlerin, sonraki yaşantılarında evliliklerinde ortaya çıkan problemlerinin çözümünde daha üst düzeyde insan ilişkileri ve iletişim becerilerini kullanabilmeleri mümkün olabilecektir. Program kapsamında ilk oturumda evlilikte ortaya çıkan problemlerle, eşlerin insan ilişkileri ve iletişim becerileri arasındaki ilişki tartışılmıştır. Bu oturumda erkek eşlerin; duygu ve düşüncelerini paylaşmadıkları, kendilerinin yaşadıkları güçlükler karşısında anlayış göstermedikleri, anlaşmazlık durumlarında saygısız ve kırıcı davrandıkları, eleştiri karşısında öfkelendikleri gibi konularda bayan eşlerin daha çok yakındıkları gözlenmiştir. İlerleyen oturumlarda ise erkek eşlerin; eleştiri karşısında öfkelenmeden dinleme, eleştiri konusunda ben dili kullanarak duygularını paylaşma ve saldırganca olmayan tarzda empatik yüzleştirme yapma becerileriyle ilgili uygulamalarda bayan eşlere göre daha çok zorlandıkları ve isteklerini dile getirirken daha çok emir cümlecikleri kullandıkları gözlenmiştir. Bayan eşlerin ise duygu, düşünce ve isteklerini paylaşırken soyut ya da genel ifadeler kullandıkları, bu durumun iletişimde belirsizliğe yol açtığı ve erkek eşlerin bu durumdan yakındıkları gözlenmiştir. Eşlerin etkili olmayan olumsuz iletişim becerilerine sahip 
olması, evlilikte ortaya çıkan problemlerin çözümünde yetersiz kalmalarına neden olabilmektedir. Bu durum eşlerin, etkili insan ilişkileri becerilerini geçmiş yaşantılarında yeterince kazanamadıklarını göstermektedir. Program uygulanırken 10 oturum süresince evli çiftlerin birbirleriyle kurdukları ilişkilerde; etkin dinleme becerisini kullanabilme, dinlerken beden dilini iletişimi devam ettirici biçimde uygulayabilme, eşinin beden dilini anlayabilme, duygularını ben dilini kullanarak ve somut bir biçimde ifade edebilme, empati kurabilme ve empatik yüzleştirme yapabilme, öfkesini fark edebilme, kontrol edebilme ve eşini kırmadan ifade edebilme ve eleştiri karşısında iletişimi sürdürme ve görüş alış-verişinde bulunma gibi becerileri kazanmalarını sağlama amacıyla uygulamalar yapılmıştır. Her oturumun sonunda ise öğrendikleri beceriyi eşleriyle kurdukları iletişimde kullanmaları için ödevlendirme yapılmıştır. Bu uygulamaların, evli çiftlerin evlilik uyum düzeyleri üzerinde etkili olduğu söylenebilir.

Yapılan bilimsel araştırmalar, değişik örneklem gruplarında uygulanan insan ilişkileri beceri eğitimi programlarının, bireylerin insan ilişkileri becerilerini olumlu yönde etkilediğini ve bu araştırmanın bulgularıyla benzerlik taşıdığını göstermektedir. Örneğin, Bulach'ın (2001) yaptığı araştırmada insan ilişkileri beceri eğitiminin bireylerin, insanlara güven ve açıklık düzeylerine olumlu yönde etkisinin olduğu saptanmıştır. Aladağ'ın (1998) yaptığ 1 araştırmada, araştırmacının geliştirdiği insan ilişkileri beceri eğitimi modelinin, deneklerin kişiler arası ilişkilerde dengelilik düzeyine önemli etkisinin olduğu saptanmıştır. Sardoğan'ın (1998) yaptığ1 araştırmada, Florida İnsan İlişkileri Beceri Eğitimi Modeli'nin grup üyelerinin kaygı, yalnızlık, kendini açma ve atılganlık düzeylerine önemli etkisinin olduğu; Hall, Hall ve Abacı'nın (1997) yaptığı araştırmada, öğretmenlerin stres, içten denetimlilik ve öğrenci kontrol anlayışında önemli etkisinin olduğu saptanmıştır.

Yurtdışında ve Türkiye'de yapılan araştırmaların bulguları, uyumlu bir evliliğin bir çok değişkenden etkilendiğini göstermektedir. Bunları özetleyerek vermek gerekirse; yeni evlilerde erkek eşin anne babaya bağımlı davranmasının (Haws \& Mallinckrodt, 1998); eşlerden birinde ya da ikisinde nevrotik ve psikotik belirtilerin yüksek olmasının (Kitamura \& at.al. 1995); evlilikte yaşanan ekonomik sıkıntıların (Kinnunen \& Feldt, 2004); erkek eşte durumluk kaygının yüksek olmasının (Dehle \& Weiss, 2002) ve kadının çalışmamasının (Nathavat \& Mathur, 1992); kendi seçimiyle değil de başkalarının yönlendirmesi yoluyla ayarlanmış evlilik yapmanın (Demir ve Fışıloğlu, 1999); eşle yaşanan çatışmanın sıklığının ve yarattığı gerginlik ile eşlerde düşük iş doyumunun (Tezer, 1994; Hatipoğlu, 1993); eşlerden birinde ortaya çıkan depresyonun (Kastro, 1988) ve eşler arasında olumsuz 
yüklemelerin kullanılmasının (Kışlak, 1997) evlilikte uyumu olumsuz yönde etkilediğini göstermektedir.

Sonuç olarak bu araştırmada elde edilen bulgular, İnsan İlişkileri Beceri Eğitimi Programı'nın evli çiftlerde evlilikte uyum sürecinin ilişkili olduğu; aile bütçesi, arkadaş ilişkileri, cinsellik, toplumsal kurallar, yaşam felsefesi, boş zaman etkinlikleri ve ev dişı etkinlikler gibi konularda ortaya çıkan problemlerin çözümünde daha etkili iletişim kurmalarına yardımcı olduğunu göstermektedir. Uyumlu bir evliliğin sürmesi açısından eşlerin her ikisinin de, iletişim sorunlarının çözümünde işlevsel olan insan ilişkileri becerilerine sahip olmalarının gerekli olduğu ileri sürülebilir.

Elde edilen sonuçlar doğrultusunda şu öneriler getirilebilir:

1. Programa katılan evli çiftlerin evlilik uyum düzeylerinde gözlemlenen olumlu gelişmenin uzun süreli etkileri araştırılabilir.

2. Araştırmacılar tarafından geliştirilen İnsan İlişkileri Beceri Eğitimi Programı'nın evli bireyler üzerindeki etkililiğini karşılaştırmalı olarak inceleme amacıyla başka araştırmalar yapılabilir.

3. Evli ya da evlenmek üzere olan çiftlere yönelik olarak verilebilecek evlilik/aile danışmanlığı hizmetlerinde, evlilik sürecinin insan ilişkileri boyutu ve ruh sağllğına etkisi üzerinde daha önemle durulabilir ve bu konuda başka araştırmalar yapılabilir.

\section{KAYNAKLAR}

Aladağ, M. (1998). The effect of human relations training program on developing interpersonal styles of university students. Ankara: Orta Doğu Teknik Üniversitesi Sosyal Bilimler Enstitüsü Yüksek Lisans Tezi.

Bulach, R.C. (2001). The impact of human relations training on levels of opennes and trust. Research for Educational Reform. 8(4), 45-57.

Carter, R. E. \& Carter, C. A. (1994). Marital adjustment and effects of ilness in married pairs with one or both spouses chronically ill. The American Journal of Family Therapy. 22 (4), 315-326.

Dehle, C. \& Weiss, R. L. (2002). Associations between anxiety and marital adjustment. The Journal of Psychology.136 (3), 328-338.

Dehle, C. \& Weiss, R.L. (2002). Associations between anxiety and marital adjustment. The Journal of Psychology.136 (3), 328-338.

Demir, A. \& Fışıloğlu, H. (1999). Loneliness and marital adjustment of Turkish couples. The Journal of Psychology. 133 (2), 230-240. 
Dowd, E. T. \& Chick, J. M. (1982). Level I human relations skilss for the occupational specialist working with groups. competency based modular series. Florida State University, Tallahassee: Center for Studies Vocational Education. 1-53.

Egan, G. (1977). You and me. California: Brooks/Cole Publishing Company.

Egan, G. (1994). Yardım becerileri alıştırmaları, Çev.: F.Akkoyun, Ankara: Form Ofset.

Güvenç, B.(1984). Insan ve kültür, 4. Basım, İstanbul: Remzi Kitabevi. 275.

Hall, E., Hall, C. \& Abaci, R. (1997). The effect of human reletions training on reported teacher stress, pupil control ideology and locus of control. British Journal of Educatioanal Psychology. 67, 483- 496.

Hatipoğlu, Z. (1993). The rol of certain demographic variables and marital conflict in marital satisfaction of husbands and wives. Ankara: Orta Doğu Teknik Üniversitesi Sosyal Bilimler Enstitüsü Yüksek Lisans Tezi. v-vi.

Haws, A.W. \& Mallinckrodt, B. (1998). Separation - Individuation from family of origin and marital adjustment of recently married couples. The American Journal of Family Therapy. 26, 293-306.

Jouriles, E. N.\& at. al. (1991). Marital adjustment, parental disagreements about child rearing and behavior problems in boys: increasing the specificity of the marital assessment. Child Development. 62, 1424-1433.

Kastro, R. M. (1998). Evlilik içi uyum ve depresyon: evlilik ilişkisinin niteliği ve eşlerde semptom oluşumu hakkında bir çalışma. İstanbul: İstanbul Üniversitesi Sosyal Bilimler Enstitüsü Yüksek Lisans Tezi.v.

Kışlak-Tutarel, Ş. (1999). Evlilikte uyum ölçeğinin (euö) güvenirlik ve geçerlik çalışması. 3P Psikiyatri Psikoloji Psikofarmakoloji Dergisi. 7(1), 54-56.

Kışlak-Tutarel, Ş. (1997). Evlilik uyumu ile nedensellik ve sorumluluk yüklemeleri arasındaki ilişkiler. Türk Psikoloji Dergisi. 12(40), 55- 63.

Kinnunen, U. \& Feldt, T. (2004). Economic stress and marital adjustment among couples: analyses at the dyadic level. European. Journal of Social Psychology. $34,519-532$.

Kitamura, T. \& at. al. (1995). Factorial structura and correlates of marital adjustment in a Japanese population: a community study. Journal of Community Psychology. 23, 117-126.

Kottak, C. P. (2001). Antropoloji: insan çeşitliliğine bir baklş. Ankara: Ütopya Yayınevi, 397.

McGovern, J. M. \& Meyers, A. S. (2002). Relation - ships between sex - role attitudes, division of household tasks and marital adjustment. Contemporary Family Therapy. 24(4), 601-618. 
Ming, V. M. W. (2002). Psychological predictors of marital adjustment in breast cancer patients. psychology. Health and Medicine. 7(1), 38-51.

Müller, A. T. \& Zyl, D. V. (1991). Relationship beliefs, interpersonal perception and marital adjustment. Journal of Clinical Psychology. 47(1), 28-33.

Nathawat, S. S. \& Mathur, A. (1992). Marital adjustment and subjective well being in Indian - educated housewives and working women. The Journal of Psychology. 127 (3), 353-358.

Nelson-Jones, R. (1986) Human relationship skills. Norwich: Typeset by Paston Press.75.

Nemechek, S. \& Olson, K. R. (1999). Five factor personality similarity and marital adjustment. Social Behavior and Personality. 27(3), 309-318.

Nutter, J. B. \& Boland, J. M. (1982). Human relations skills in individual interactions for the occupational specialist. competency based modular series. Florida State University, Tallahassee: Center for Studies Vocational Education. $1-75$.

Özuğurlu, K. (1985).Evlilik raporu. İstanbul: Altın Kitaplar Yayınevi, 67.

Peterson, B. D., Newton, C. R. \& Rosen, K. H. (2003). Examining congruence between partners perceived infertility - related stress and its relationship to marital adjustment and depression in infertile couples. Family Couples. 42(1), 59-70.

Reece, B. L. \& Brandt, R. (1990). Human relations principles and practices. Boston: Houghton Mifflin Company.

Risdal, D. \& Singer, H. S. G. (2004). Marital adjustment in parents of children with disabilities: a historical review and meta - analysis. Researh and Practice for Persons with Severe Disabilities. 29(2), 95 -103.

Sabatelli, R. M. (1988). Measurement 1ssues in marital research:a review and critique of contemporary survey instruments. Journal of Marriage and the Family. 50, 891-915.

Sardoğan, M. E. (1998). Florida insan ilişkileri becerileri ĕgitimi modelinin grup üyelerinin kaygl, yalnızlık, atılganlık, kendini açma ve empatik beceri düzeylerine etkisi. Samsun: Ondokuz Mayıs Üniversitesi Sosyal Bilimler Enstitüsü Doktora Tezi. i.

Schanake, M. E. (1990). Human relations. Ohio: Merrill Publishing Company.

Scott, B. (1988). Interpersonal communications: a human relations practicum. training module vill. desegration assistance center - south central collabarative. San Antonio: Intercultural Development Research Association. $1-74$. 
Sinha, S. P. \& Mukerjee, N. (1989). Marital adjustment and personal space orientation. The Journal of Social Psychology. 130(5), 633-639.

Spanier, G. (1976). Measuring dyadic adjustment: new scales for assessing the quality of marriage and similar dyads. Journal of Marriage and the Family.38, $15-28$.

Stahlhut, R. \& Hawkes, R. (1994). Human relations training for students teachers. a paper presented association of teacher educators 74 th annual meeting. Atlanta: GA Feb12-16, 1-7.

Stitt, B. \& Stitt, T. (1990). Human relations skills: activity to increase life and career successes for women. Educational Resources Information Center. 1-65.

Tezer, E. (1994). Evlilik ve iş doyumu ilişkisi: ikili çatışmalar ve bazı demografik değişkenlerin rolü. Psikolojik Danışma ve Rehberlik Dergisi. 2(1), 1-8.

Transitional black women's project: human relations training handbook. (1983). Women's Institute of the Southeast, Atlanta: Atlanta University Center, Women's Educational Equity Act Program. 1- 67. 